Arcidiácono, P. Madres privadas de libertad (y de las Asignaciones Familiares). Resistencias burocráticas y actuación judicial. Derecho y Ciencias Sociales. Octubre 2017. No 17. Pgs 207-225 ISNN 1852-2971. Instituto de Cultura Jurídica y Maestría en Sociología Jurídica. FCJ y S. UNLP

\title{
Madres privadas de libertad (y de las Asignaciones Familiares). Resistencias burocráticas y actuación judicial
}

\author{
Mothers deprived of their liberty (and Family Allowances). Bureaucratic resistance and \\ judicial action.
}

\section{Pilar Arcidiácono}

\section{Resumen}

Las madres que conviven con sus hijos menores de cuatro años en contexto de encierro no acceden a cobrar Asignaciones Familiares, situación de exclusión que llegó a plantearse en sede judicial y tuvo sentencia favorable. Esto sucede en Argentina en paralelo a la masificación del sistema de Asignaciones Familiares.

Este artículo retomará este caso judicial para identificar y recuperar actores, temas y nudos problemáticos que atraviesan la temática de las Asignaciones Familiares, tema central en la agenda de la política social.

Se busca dar respuesta a los siguientes interrogantes: ¿qué actores, en qué contextos y a través de qué prácticas logran sostener esta exclusión?; ¿qué razones argumentan y por medio de qué mecanismos institucionales se concretan estas restricciones?

Para ello, se toma distancia de abordajes de políticas públicas que suponen coherencia, racionalidades lineales o visiones totalizadoras sobre el Estado y los gobiernos. Este tipo de acercamientos no permitiría comprender el hecho de que las restricciones vinculadas con el acceso a las Asignaciones son contemporáneas a la misma gestión de gobierno que amplío el Sistema de Asignaciones y que siguen vigente durante la nueva administración de Cambiemos que continuo extendiendo las prestaciones.

Palabras Clave: Asignaciones familiares; madres privadas de libertad; burocracias; masividad; exclusiones.

\begin{abstract}
Mothers who live with their children under four years of age in the context of confinement do not agree to collect family allowances. This happens in Argentina at the same time as the system of Family Allowances was overwritten.

This exclusion came to be raised in court and had a favorable ruling. This article resumes judicial case functions as a trigger that allows identifying and recovering problematic actors, themes and knots that cross the issue of Family Allowances, a central issue in the social policy agenda.

It seeks to answer the following questions: what actors, in what contexts and through which practices can sustain this exclusion, what reasons argue and through what institutional mechanisms are these restrictions concretized? To do this, it takes distance from public policy approaches that imply coherence, linear rationalities or totalizing visions on the State and governments. This type of approach would not allow us to understand the fact that these
\end{abstract}

•Politóloga, Magíster en Políticas Sociales, Doctora en Cs. Ss, UBA. Investigadora de CONICET (Instituto de Inv. Jur y Soc. "Ambrosio L. Gioja” de la Facultad de Derecho -UBA). Prof.Adj. de .Ciencia Política del Ciclo Básico Común y de Sociología Política de la carrera de Sociología (UBA). Docente de posgrados relacionados con el campo de las políticas sociales (UBA- UNLP)

Recibido: 2/6/2017. Aceptado con correcciones 6/10/2017 
Arcidiácono, P. Madres privadas de libertad (y de las Asignaciones Familiares). Resistencias burocráticas y actuación judicial. Derecho y Ciencias Sociales. Octubre 2017. № 17. Pgs 207-225 ISNN 1852-2971. Instituto de Cultura Jurídica y Maestría en Sociología Jurídica. FCJ y S. UNLP

restrictions on access to Allowances are contemporaneous with the same governance that extended the System of Allocations and that they are not reversed with the new administration of Cambiemos that continues to extend the benefits.

Key words: Family allowances; mothers deprived of liberty; bureaucracies; mass; exclusions. 
Arcidiácono, P. Madres privadas de libertad (y de las Asignaciones Familiares). Resistencias burocráticas y actuación judicial. Derecho y Ciencias Sociales. Octubre 2017. No 17. Pgs 207-225 ISNN 1852-2971. Instituto de Cultura Jurídica y Maestría en Sociología Jurídica. FCJ y S. UNLP

\section{Madres privadas de libertad (y de las Asignaciones Familiares). Resistencias burocráticas y actuación judicial}

Pilar Arcidiácono

\section{1-Introducción}

En un contexto de creciente masificación del sistema de Asignaciones Familiares, las personas privadas de libertad (PPL) no acceden en general a estas prestaciones. Este artículo concentrará la atención en el grupo de las madres que conviven con sus hijos menores de cuatro años en contexto de encierro. Este tema llegó a la sede judicial, con la presentación de un habeas corpus que abarca 35 mujeres del Centro Federal de Detención de Mujeres (12 embarazadas y 23 detenidas con niños) - Unidad 31 de Ezeiza, proceso del que participé junto con un grupo de colegas en calidad de Amicus Curiae ${ }^{l}$.

Cabe recordar que en el nuevo siglo Argentina amplía el sistema de Asignaciones Familiares. Por un lado, continúan vigente las tradicionales Asignaciones Familiares (AAFF) destinadas a trabajadores formales que surgieron en la legislación argentina a mediados de la década del treinta con el subsidio a la maternidad, bajo la lógica de una política contributiva, y desde allí experimentaron procesos de consolidación hasta la sanción de la ley 24.714 en $1996^{2}$. Concretamente, desde 2004 de la mano de la recuperación del mercado de trabajo,las AAFF no sólo ampliaron su cobertura sino que también se tomó la decisión de aumentar sistemáticamente sus montos que estaban congelados desde 1996, aunque quedaron intactos los esquemas propios de la reforma de la década de los noventa ${ }^{3}$.

Por otro, frente a los sostenidos niveles de informalidad, en 2009 se creó la Asignación Universal por Hijo (AUH) y en 2011 la Asignación por Embarazo (AE) que implicaron cambios cuali y cuantitativos respecto de las intervenciones previas. Se incorporaron dentro del sistema de la seguridad social a los hijos de los trabajadores del sector informal y de las

\footnotetext{
${ }^{1}$ El amicus curiae (amigo de la corte o amigo del tribunal) refiere a presentaciones realizadas por terceros ajenos a un litigio, que ofrecen voluntariamente su opinión frente a algún punto de derecho u otro aspecto relacionado, para colaborar con el tribunal en la resolución de la causa. También se presentaron como amicus el Centro de Estudios Legales y Sociales (CELS) y la Dra. Elsa Porta (ex Jueza de la Cámara Nacional de Apelaciones del Trabajo).

${ }^{2}$ Esa ley eliminó las prestaciones a los salarios más altos y estableció un monto escalonado de transferencias inversamente proporcionales al ingreso. La reforma tuvo el objetivo de disminuir los costos laborales al reducir las alícuotas que pagaban los empleadores. La modificación supuso un cambio de paradigma: mientras las AAFF habían cubierto históricamente las contingencias familiares, a partir de la nueva ley la protección de tales circunstancias pasaron a ser dependientes de los niveles salariales pues se establecieron tres rangos salariales y montos de transferencia inversamente proporcionales a los ingresos.

${ }^{3}$ Para un análisis del sistema de AAFF en Argentina, ver: Bertranou y Bonari, 2005; Hintze y Costa, 2011; Arcidiácono et al, 2015; entre otros.
} 
Arcidiácono, P. Madres privadas de libertad (y de las Asignaciones Familiares). Resistencias burocráticas y actuación judicial. Derecho y Ciencias Sociales. Octubre 2017. No 17. Pgs 207-225 ISNN 1852-2971. Instituto de Cultura Jurídica y Maestría en Sociología Jurídica. FCJ y S. UNLP

trabajadoras domésticas, de los desocupados y de los trabajadores temporarios registrados del sector agropecuario.

El campo de las Asignaciones se convirtió en un eje central de la política social de la administración de Nestor Kirchner (para el caso de los asalariados) y luego de Cristina Fernández (con la creación de la AUH y AE). Implicó que la Administración Nacional de la Seguridad Social (ANSES) ganara protagonismo en temas no contributivos a partir de la AUH y del surgimiento de un conjunto de medidas posteriores. ${ }^{4}$.

A nivel cuantitativo, según datos oficiales de la Encuesta Nacional de Protección y Seguridad Social del (MTEySS, 2014), a partir de todas estas transformaciones en el Sistema de Asignaciones Familiares, Argentina logró cubrir el 75 por ciento de niños/as menores de 18 años. Del resto, la mitad se encuentra sin cobertura por problemas en los trámites o falta de Documento Nacional de Identidad y los otros por el propio recorte normativo de las AAFF/AUH.

Los datos indican que para junio de 2016, 3.922.156 niños recibían AUH y 4.057.871 AAFF (MTEySS, 2016). Más allá de las variaciones a lo largo de estos años la cobertura no descendió a menos de 3,5 millones en cada una de las prestaciones. Esto da cuenta de la masividad del Sistema de Asignaciones en Argentina. Es en este contexto donde se excluye a las mencionadas 35 mujeres madres privadas de libertad.

Como estrategia metodológica, en este artículo el caso judicial funciona como un disparador que permite identificar y recuperar actores, temas y nudos problemáticos que atraviesan la temática de las Asignaciones Familiares. El análisis aquí propuesto toma distancia de abordajes de políticas públicas que suponen coherencia, racionalidades lineales o visiones totalizadoras sobre el Estado, los gobiernos y las burocracias. Este tipo de aproximaciones no permitiría comprender el hecho de que estas restricciones son contemporáneas a la misma gestión de gobierno que amplio las Asignaciones y que tampoco se revierten con la nueva administración de Cambiemos que continuo extendiendo las AAFF a sectores monotributistas que se encontraban excluidos del sistema.

Lo que a primera vista podría ser catalogado como un "desvío" del espíritu fundacional de las Asignaciones, será analizado en este artículo como parte del entramado de la política pública. Para ello se invierte el procedimiento analítico (Perelmiter, 2008) y se indaga sobre las razones, expectativas y visiones que los actores políticos (tomadores de decisiones, jueces o

\footnotetext{
${ }^{4}$ Para un detallado recorrido sobre los cambios en el Sistema de las Asignaciones, cfr Arcidiáconoet al, 2015.
} 
Arcidiácono, P. Madres privadas de libertad (y de las Asignaciones Familiares). Resistencias burocráticas y actuación judicial. Derecho y Ciencias Sociales. Octubre 2017. No 17. Pgs 207-225 ISNN 1852-2971. Instituto de Cultura Jurídica y Maestría en Sociología Jurídica. FCJ y S. UNLP

burócratas técnico profesionales) tienen sobre estas temáticas ${ }^{5}$. En otras palabras, ¿qué actores, en qué contextos y a través de qué prácticas logran sostener esta exclusión? ¿Qué razones argumentan y por medio de qué mecanismos institucionales se concretan estas restricciones?

Se pretende captar una suerte de "película completa" y no una simple "foto" del caso judicial, razón por la cual el análisis no se limitó a una lectura de las sentencias, elección frecuente en las aproximaciones jurídicas/jurisprudenciales sobre los casos. Se recuperaron diversas piezas del expediente judicial (demanda, sentencias de las diferentes instancias, apelaciones, actas de las audiencias mantenidas entre las partes, dictámenes y notas de ANSES, amicus curiae, entre otros elementos). Esto supone que los expedientes ${ }^{6}$ hablan de acontecimientos, registran procesos, instituyen relaciones de conocimiento y prácticas dentro del aparato legal e incluso establecen los límites de su propia realidad, esto es, de la realidad del saber jurídico (Barrera, 2014: 78). En otras palabras implica sostener que el derecho que emerge de la sentencia se vincula con las relaciones de poder entre los titulares de diversos tipos de capital jurídico que operan en el campo (Bourdieu, 2000).

La posibilidad de actuar como Amicus Curiae en la causa ofreció un lugar específico y a la vez privilegiado para el acceso al material y para realizar entrevistas en profundidad a las diferentes partes involucradas en el litigio y actores centrales en materia de derechos sociales en cárceles ${ }^{7}$.

\section{2- El caso judicial: Habeas corpus en representación de las madres de libertad que conviven con sus hijos y no cobran Asignaciones Familiares}

\footnotetext{
${ }^{5}$ Perelmiter (2008: 12) sostiene que estas miradas no sólo desatienden procesos sociopolíticos importantes cuyo locus es el Estado, sino que interpretan como carencias o distorsiones realidades que podrían ser pensadas en su productividad y singularidad política. Más allá de las objeciones propiamente teóricas, la autora señala que en la realidad empírica de los Estados ningún agente en particular tiene influencia o autoridad uniforme a lo largo de todos los sectores estatales, y la acción estatal no es ni centralizada ni coherente.

${ }^{6}$ En general los expedientes no son foco de interés en sí mismos, y ciertamente no se vuelven objetos de investigación científica para los estudios del derecho. Como sostiene Vismann (2008:35): "Los expedientes son instrumentos molestos, bestias incesantemente engendradas que deben ser encarceladas y domesticadas" En cambio otras profesiones como los lingüistas, sociólogos e historiadores aprecian a los expedientes por sus cualidades auto-documentales.

${ }^{7}$ Se realizaron entrevistas en profundidad a burócratas técnico profesionales de: la Procuración Penitenciaria de la Nación (2), la Defensoría General de la Nación (1); Servicio Jurídico Permanente de ANSES (2), Área de Emisión de Normas y Requerimientos de Asignaciones no contributivas (1), ENCOPE (1). Asimismo se entrevistaron expertos académicos y ex funcionarios judiciales en materia de derechos sociales de las personas privadas de libertad (3). Se hace uso del masculino como denominación general de los cargos y funciones a fin de preservar la identidad de las personas entrevistadas
} 
Arcidiácono, P. Madres privadas de libertad (y de las Asignaciones Familiares). Resistencias burocráticas y actuación judicial. Derecho y Ciencias Sociales. Octubre 2017. № 17. Pgs 207-225 ISNN 1852-2971. Instituto de Cultura Jurídica y Maestría en Sociología Jurídica. FCJ y S. UNLP

La legislación penal argentina habilita a que las madres puedan convivir con sus niños en contexto de encierro $^{8}$. ¿Cuántas mujeres hacen uso de esta opción? En el expediente judicial figura un parte de población remitido por el Servicio Penitenciario Federal (SPF) correspondiente al 17 de octubre de 2014- dos meses previos a la presentación de la demanda. Allí se señala la existencia de un total de 761 detenidas; 18 de ellas están embarazadas y 48 son madres que se encuentran acompañadas por un total de 51 niños y niñas (la mayoría de ellos menores a un año). De este total, en el Centro Federal de Detención de Mujeres (U-31) que tiene capacidad para 130 personas, se alojan 92 mujeres de las cuales al momento de inicio de este caso, 12 estaban embarazadas y 23 eran acompañadas por sus hijos e hijas (que sumaban 25). Sin dudas, por las propias características esta población es dinámica, aunque suele mantenerse relativamente estable (PPN, 2015) y es cuantitativamente insignificante si se lo coloca a la luz de los procesos de masificación que tuvieron las Asignaciones Familiares.

Las Reglas de Brasilia sobre acceso a la justicia de las personas en condición de vulnerabilidad, destacana las personas privadas de la libertad dentro de este universo ${ }^{9}$. Un estudio realizado hace algunos años por la PPN, el Centro de Estudios Legales y Sociales (CELS) y el Ministerio Público de la Defensa $(2011)^{10}$ indica que el promedio de edad de las mujeres detenidas ronda los 36 años. A la hora de ser detenidas, muchas encabezan una familia monoparental y ejercen la jefatura del hogar. De hecho, el 63,5\% era el principal sostén económico de su grupo familiar y el $25 \%$ dijo seguir aportando dinero a su hogar. La mayoría de estas mujeres no registran antecedentes, fueron procesadas o condenadas por delitos no violentos y pertenecen a sectores social y económicamente desfavorecidos. Para cubrir estas necesidades, la mayoría de las detenidas recurren a la ayuda de su familia (61\%) o al intercambio de bienes con sus compañeras (27,8\%). Otras dependen de donaciones (11\%) o deben gastar su peculio (PPN, CELS y Ministerio Público de la Defensa, 2011). En la presentación del habeas corpus se destaca que el monto que muchas de ellas destinan mensualmente a este fin es prácticamente el mismo que se abona por Asignaciones como la AUH. Asimismo, el acceso a trabajo al interior de la cárcel les resulta más dificultoso a las

\footnotetext{
${ }^{8}$ Opción del artículo 195 de la Ley $\mathrm{N}^{\circ} 24.660$ (sobre ejecución de la pena privativa de libertad) “La interna podrá retener consigo a sus hijos menores de cuatro años. Cuando se encuentre justificado, se organizará un jardín maternal a cargo de personal calificado". Como señala la PPN (2015) este sistema sigue vigente a pesar de la aprobación de la Ley $\mathrm{N}^{\circ}$ 26.472, que amplió los supuestos de procedencia del arresto domiciliario incluyendo el caso de mujeres embarazadas y madres de niños menores de cinco años.

${ }^{9}$ Sección 2a "Beneficiarios de las reglas", 10. Privados de libertad (22).Las Reglas fueron aprobadas en la XIV Cumbre Judicial Iberoamericana, realizada en Brasilia, en 2008.

${ }^{10}$ Para mayor detalle sobre el perfil poblacional pueden consultarse los diferentes informes de la Procuración Penitenciaria de la Nación. Disponibles en http://www.ppn.gov.ar/?q=informes-anuales
} 
Arcidiácono, P. Madres privadas de libertad (y de las Asignaciones Familiares). Resistencias burocráticas y actuación judicial. Derecho y Ciencias Sociales. Octubre 2017. No 17. Pgs 207-225 ISNN 1852-2971. Instituto de Cultura Jurídica y Maestría en Sociología Jurídica. FCJ y S. UNLP

madres con niños o embarazadas que sólo pueden desempeñar tareas por lapsos limitados y cuya trayectoria es muy dinámica ${ }^{11}$. Por esta razón, muchas de estas mujeres podrían acceder potencialmente tanto al sistema de AAFF como al esquema no contributivo de las Asignaciones (AUH y AE).

Sin embargo, el hecho de que la población privada de libertad (PPL) que trabaja en la cárcel no acceda a las Asignaciones Familiares es una cuestión de larga data e instalada como parte del repertorio de los derechos sociales vulnerados en contexto de encierro, aspecto que es abordado por otros litigios, tal como se mencionará más adelante. Diferente es el caso de la AUH que por su propia normativa y luego de gestiones puntuales de la Procuración Penitenciaria de la Nación (PPN), se facilitó el acceso a esta prestación por medio de la figura de los apoderados cuando el titular se encuentra privado de su libertad. El artículo $17^{\circ}$ de la Resolución No 393/09 de la ANSES prevé especialmente esta situación. Sin embargo, en la práctica, tampoco acceden a esta prestación. Según la Procuración Penitenciaria de la Nación (PPN, 2015), el principal problema está relacionado con la falta de información a los presos y las trabas burocráticas de diverso tipo, como por ejemplo para entregar el correspondiente formulario de otorgamiento de poder o certificar la firma del detenido (Borda, 2014)

El grupo de madres que este artículo refiere también es excluido de la AUH a partir de un dictamen del Servicio Jurídico Permanente de ANSES que se convierte en una pieza jurídica y política central para justificar la exclusión del mencionado grupo, sosteniendo como argumento que las necesidades de madres e hijos ya están cubiertas por otras agencias del Estado (principalmente el SPF) ${ }^{12}$.

Para este grupo donde el pago de las Asignaciones no pudo resolverse por la vía administrativa y ante las resistencias de ANSES cristalizadas en el mencionado dictamen, se recurrió a los tribunales de justicia. La PPN interpuso un habeas corpus colectivo correctivo en el Juzgado Federal en lo Criminal y Correccional Número 1 de Lomas de Zamora para las madres privadas de libertad alojados en el Centro Federal de Detención de Mujeres - Unidad

\footnotetext{
${ }^{11} \mathrm{El}$ trabajo en contextos de encierro tiene pocas áreas laborales relacionadas con oficios o profesiones, sólo funcionan unos pocos talleres de sastrería, jardinería, reparación de motores y carpintería.Si se agrupan las actividades que la propia administración penitenciaria considera como talleres productivos (costura, confección de bolsas, encuadernación), éstas concentran el $45,2 \%$ de las trabajadoras, mientras que el 54,8\% realiza tareas definidas como laborterapia. Esta diferencia conceptual (trabajo productivo y no productivo), aunque no aparezca de modo claro en el discurso oficial, remite a la diferencia entre actividades que crean bienes y, por lo tanto, plusvalor, que además aportarían cierta formación a las trabajadoras, y aquellas destinadas al mantenimiento de la institución y que sólo contribuyen a "hacer pasar el tiempo" y se vinculan con actividades de mantenimiento del propio lugar de encierro. Para el caso de las mujeres, entre costura, cocina y fajina concentran el 75\% de las tareas realizadas (PPN, CELS y MPD, 2011).

${ }^{12}$ Para conocer las modalidades, razones y sentidos de las exclusiones vinculadas con la AUH, cfr. Arcidiácono (2016)
} 
Arcidiácono, P. Madres privadas de libertad (y de las Asignaciones Familiares). Resistencias burocráticas y actuación judicial. Derecho y Ciencias Sociales. Octubre 2017. № 17. Pgs 207-225 ISNN 1852-2971. Instituto de Cultura Jurídica y Maestría en Sociología Jurídica. FCJ y S. UNLP

31 de Ezeiza" ${ }^{13}$. Como investigadores del Grupode Trabajo Interdisciplinario "Derechos Sociales y Políticas públicas" de la Universidad de Buenos Aires" nos presentamos bajo la figura de Amicus Curiae en dicha causa.

La reconstrucción del caso a lo largo del trabajo de campo incluyó algunos interrogantes sobre las decisiones tomadas por quienes promovieron la demanda: ¿Por qué se presentó un habeas corpus y no un amparo?; ¿Por qué se recurrió al fuero penal y no a la seguridad social si se trataba de un caso de Asignaciones Familiares? Algunas pistas se encontraron en las entrevistas realizadas a los responsables tanto de la PPN como de Defensoría General, y dan cuenta de algunas tensiones que atraviesan a las mismas personas, pero que luego se desdibujan en esa pieza que se presenta como cerrada (el texto final del habeas corpus).

Un conjunto de argumentos pragmáticos ganaron terreno a la hora de diseñar la estrategia del caso. Estos presentan diversas aristas y pueden sintetizarse de la siguiente manera. A nivel de procesal, primó el convencimiento de que la vulneración (la exclusión de las madres de las Asignaciones) generaba un "agravamiento en las condiciones de detención" de las mujeres y sus hijos, aspecto que procesalmente justificaba la presentación de un habeas corpus como garantía constitucional. A la vez, a nivel pragmático, los actores que litigan supusieron encontrar menos experticia en los equipos legales de ANSES para tramitar un habeas corpus, al estar mayormente familiarizados con los recursos de amparo vinculados con temas previsionales que tienen sede en la seguridad social. Esto podría ofrecer un panorama más alentador para la tramitación del caso.

Segundo, a nivel jurisprudencial, había algunos antecedentes en materia de PPL y derechos sociales (incluso de diferentes salas de la Cámara de Casación Penal) que los propios actores de la PPN y de la Defensoría General de la Nación evaluaron como "auspiciosos". Sobre todo entre 2012 y 2014 diversa jurisprudencia fue proclive al reconocimiento de derechos sociales en contextos de encierro y más allá de su efecto jurídico, estos fallos pueden ser leídos en clave de sus "mensajes políticos" (Abdó Feréz, 2014: 53). A modo de ejemplo y por sus efectos en la agenda mediática y política, menciono el fallo de la Sala II de la Cámara Federal de Casación Penal, en autos "Kepych, Yúriy Tibériyevich s/ recurso de casación" (con sentencia del 01/12/14). Este caso dispuso que se dictara un reglamento por parte del Ente de Cooperación Técnica del Servicio Penitenciario Federal ENCOPE

(organismo descentralizado del SPF creado en 1994 por Ley $\mathrm{N}^{\circ}$ 24.372), para regular el trabajo penitenciario y convocó a conformar una Comisión Especial de Estudio sobre las

\footnotetext{
${ }^{13}$ Para una descripción detallada sobre la causa, cfr Procuración Penitenciaria de la Nación (2015) (pp.368 a 373) http://www.ppn.gov.ar/sites/default/files/Informe\%20Anual\%202015_0.pdf.
} 
Arcidiácono, P. Madres privadas de libertad (y de las Asignaciones Familiares). Resistencias burocráticas y actuación judicial. Derecho y Ciencias Sociales. Octubre 2017. No 17. Pgs 207-225 ISNN 1852-2971. Instituto de Cultura Jurídica y Maestría en Sociología Jurídica. FCJ y S. UNLP

Condiciones de Vigencia y Estado de las Relaciones Laborales en el Marco del Trabajo Prestado en Condiciones de Encierro de las Personas Privadas de su Libertad Ambulatoria ${ }^{14}$ (en adelante "la Comisión").

Tercero, en cuanto a las demoras, se evaluó la celeridad que podía tener este tipo estrategia en comparación con los tiempos propios de la tramitación de los amparos, recursos que se ordinarizaron en un fuero colapsado de casos como es el de Seguridad Social.

Este conjunto de argumentos se impuso sobre una línea más principista que estaba presente en los mismos actores que litigaron el caso. Allí se sostenía que la presentación ante el fuero penal en causas que involucran derechos sociales alimenta visiones restrictivas sobre las vulneraciones que sufre la PPL y fortalece el rol monopólico que suele tener el Servicio Penitenciario Federal y los actores del sistema penal en todas las problemáticas vinculadas con el diverso abanicos de vulneraciones que atraviesan la vida en prisión.

Continuando con el relato del proceso, el 29 de mayo de 2015 la instancia judicial rechazó la vía del habeas corpus por comprender (como es frecuente en estos casos) que "no existe situación que constituya un agravamiento ilegítimo en la forma y las condiciones de detención de las amparistas que habilite la vía" y sólo exhorta al SPF a que tome conocimiento de esta situación sin avanzar más sobre el punto. El 11 de agosto de 2015 la Sala III de la Cámara Federal de La Plata, por mayoría, confirmó la decisión del juez de grado.

Sin embargo, el 4 de diciembre de 2015, la Sala IV de la Cámara Federal de Casación Penal hizo lugar a la acción. El voto mayoritario de los jueces Gustavo Hornos y Mariano Borinsky, luego de argumentar en favor de la pertinencia del habeas corpus colectivo como mecanismo procesal para plantear el problema denunciado, destaca que "las mujeres privadas de su libertad son sujetos del derecho a la seguridad social, y, como tales, tienen derecho a las diferentes prestaciones establecidas en la ley 24.714". En especial, enfatizaron que cuando el legislador quiso excluir alguna situación de las previsiones del régimen de Asignaciones Familiares lo hizo y que, por tal razón, "donde la ley no distingue no cabe distinguir". Respecto de la situación en particular de las mujeres madres detenidas que trabajan en prisión, ambos jueces señalaron que, dado que efectúan los aportes correspondientes, como cualquier trabajador formal, quedan comprendidas dentro del régimen de AAFF. También resaltan que "la concesión del subsidio reclamado contribuirá en forma directa a mejorar las condiciones

\footnotetext{
${ }^{14}$ Esta Comisión fue creada por Resolución Na 1373/2012 del Ministerio de Trabajo, Empleo y Seguridad Social. Conformada por Universidades, CGT, CTA, Unión Industrial, Asociación Argentina de Derecho e trabajo y Seguridad Social, Centro de Estudios de Ejecución Penal y personas que habían sido detenidas.
} 
Arcidiácono, P. Madres privadas de libertad (y de las Asignaciones Familiares). Resistencias burocráticas y actuación judicial. Derecho y Ciencias Sociales. Octubre 2017. No 17. Pgs 207-225 ISNN 1852-2971. Instituto de Cultura Jurídica y Maestría en Sociología Jurídica. FCJ y S. UNLP

de los menores alojados en la unidad penitenciaria, en evidente resguardo y protección de su interés".

Frente a esto, ANSES presentó un Recurso Extraordinario Federal declarado inadmisible por la misma Sala de la Cámara de Casación Penal el 14 de julio de 2016. En este recurso los argumentos centrales giraron en torno a la "manifiesta arbitrariedad" y a errores en el proceso de notificación que vulneraron el "derecho a la defensa". En cuanto al contenido se insistió con los esgrimidos a lo largo de todo el proceso y que pueden sintetizarse de la siguiente manera. Por un lado siguiendo con lo establecido por el Servicio Penitenciario se afirma que no corresponde abonar AAFF al no existir relación de dependencia como se entiende en la Ley de Contrato de Trabajo ${ }^{15}$. Por otro, apelando al dictamen de autoría de ANSES, se sostiene que no corresponde abonar AUH porque las necesidades de las madres y sus hijos están cubiertas. A esto se suman argumentos que frecuentemente utilizados en este tipo de casos, que resaltan el perjuicio que ocasiona la intervención judicial en causas donde se dirimen políticas públicas, al afectar entre otras los principios de la división de poderes y el erario público ${ }^{16}$.

Frente al rechazo del Recurso, ANSES presentó un Recurso de Queja ante la Corte Suprema de Justicia de la Nación que aún no fue resuelto pero que procesalmente no suspende la ejecución de la sentencia. De hecho, al momento de finalizar la escritura de este artículo, diversas agencias se encuentran trabajando para concretar el pago de las Asignaciones.

El centro de la discusión gira en torno a la fecha de retroactividad del pago. Otras cuestiones que se presentan en la ejecución, se vinculan con la necesidad de confeccionar listados que permitan contar con información actualizada del binomio madre/hijo-a (Documento Nacional de Identidad-DNI, Código Único de Identificación Laboral-CUIL) y establecer mecanismos de pago bancarizados. Durante las audiencias de ejecución, las agencias gubernamentales enfatizaron las dificultades de tipo "informáticas", como el principal obstáculo que resolver. Concretamente se requiere que la Administración Federal de Ingresos Públicos (AFIP) genere un Código para identificación de trabajadores en contextos de encierro que luego ANSES pueda utilizar para habilitar los pagos en coordinación con el SPF.

El transcurrir del proceso judicial fue confirmando muchas de las especulaciones que se reconstruyeron sobre el diseño y las estrategias del habeas corpus. Se logró el reconocimiento

\footnotetext{
${ }^{15}$ En el marco del Recurso, ANSES señala: "Al no haber ninguna modalidad de contratación laboral, no se aplica la ley de contrato de trabajo, y en consecuencia no corresponde la aplicación de la ley de asignaciones familiares, exponiendo en tal sentido que las internas no efectúan los aportes correspondientes".

${ }^{16}$ Para una discusión sobre temas clásicos y actualizados sobre litigio en derechos sociales, cfr. Arcidiáconoet al (2010); Abramovich y Pautassi (2009).
} 
Arcidiácono, P. Madres privadas de libertad (y de las Asignaciones Familiares). Resistencias burocráticas y actuación judicial. Derecho y Ciencias Sociales. Octubre 2017. № 17. Pgs 207-225 ISNN 1852-2971. Instituto de Cultura Jurídica y Maestría en Sociología Jurídica. FCJ y S. UNLP

de la vía aunque recién en la sentencia de la Cámara de Casación Penal; el caso procesalmente demoró sólo un año (contando desde la presentación de la demanda hasta la sentencia de la Casación y sin desconocer que aún se encuentra el proceso de ejecución de sentencia y la resolución del Recurso de Queja por parte de la CSJN); y la falta de experticia de ANSES para conocer el trámite de los habeas emerge de los testimonios de los propios actores de ANSES entrevistados que dejan entrever cierta "incomodidad" frente a este formato y por parte de los actores judiciales y de los demandantes que permanentemente hacen referencia a la "pobreza" de los escritos y al desconocimiento general sobre este tipo de procesos.

\section{3- Resistencias en torno al pago de Asignaciones Familiares para las madres privadas de libertad.}

a- Trabajo en contexto de encierro: sin derecho a las Asignaciones

Los instrumentos de Naciones Unidas ${ }^{17}$, la propia Organización Internacional del Trabajo (Convenio ${ }^{\circ} 29$ relativo a la prohibición del trabajo forzoso o la Convención Americana de Derechos Humanos (art.6 ap.1 y 2) señalan que el trabajo en contextos de encierro no es trabajo forzoso, le ponen condiciones expresas y sostienen la necesidad de garantizar que el trabajo sea voluntario (en términos de no obligatorio). Elsa Porta (2016) ex jueza laboral y quien también participó como Amicus Curiae en esta causa, publicó el primer libro que sintetiza la situación del trabajo en contexto de encierro en Argentina. Allí señala que tanto la mencionada Ley $\mathrm{N}^{\circ} 24.660$ sobre ejecución de la pena privativa de libertad y el reglamento general de procesados hacen referencia al trabajo remunerado de las PPL. En la regulación sobre las condiciones laborales de los internos, específicamente se detalla que el trabajo “respetará la legislación laboral y de seguridad social vigente” (artículo 107 inciso g). Asimismo expresamente se dispone que la organización del trabajo atenderá a “(...) las normas establecidas en la legislación inherente al trabajo libre" (artículo 117) y dispone "de la retribución del trabajo del interno se deducirán los aportes correspondientes a la seguridad social" (artículo 121).

En Argentina, en el siglo XXI, todavía el trabajo en contexto de encierro no está asociado con la posibilidad de obtener derechos sociales como habilita el trabajo asalariado registrado en el medio libre desde de la consolidación de los esquemas protectorios de bienestar.

\footnotetext{
${ }^{17}$ Se hace referencia a las Reglas mínimas para el tratamiento de los reclusos de las Naciones Unidas (1977), a los Principios básicos para el tratamiento de los reclusos de las Naciones Unidas (1990), y a las Reglas de las Naciones Unidas para el tratamiento de las reclusas y medidas no privativas de la libertad para las mujeres delincuentes (Reglas de Bangkok),2011).
} 
Arcidiácono, P. Madres privadas de libertad (y de las Asignaciones Familiares). Resistencias burocráticas y actuación judicial. Derecho y Ciencias Sociales. Octubre 2017. № 17. Pgs 207-225 ISNN 1852-2971. Instituto de Cultura Jurídica y Maestría en Sociología Jurídica. FCJ y S. UNLP

Los clásicos trabajos de Michael Foucault fueron pioneros para pensar el proceso de invención de la penalidad por detención en los siglos XVIII y XIX como alternativa al castigo corporal y la forma civilizada de la pena como mecanismo jurídico económico por un lado y como técnica disciplinar por otro (Foucault; [1976] 1999: 235). "La cárcel aparece como institución completa y austera, atravesada por la omnidisciplina, y la regulación total del tiempo, la comida y la palabra”. En ese marco Foucault recupera el trabajo como agente de transformación penitenciaria, vinculado directamente con el temor a la ociosidad y también en clave de los valores que hacen a la disciplina, los hábitos de orden y la obediencia que genera.El caso argentino da cuenta de que el trabajo en contextos de encierrosuele quedar reducido a un intercambio mercantil o al potencial disciplinador que refería Foucault. Las PPL en general encuentran más variadas dificultades para acceder a las prestaciones de la seguridad social (cobertura de las Aseguradoras de Riesgos de Trabajo, obra social, jubilaciones y pensiones), no sólo a las Asignaciones Familiares que aquí nos ocupan ${ }^{18}$, tema que recientemente fue objeto de abordajes por los tribunales del país.

En un extenso informe llamado Trabajo en cárceles (2015), la Comisión destinada a revisar estos temas, señaló la absoluta concordancia del trabajo en contexto de encierro con la Ley de Contrato de Trabajo (LCT) y específicamente el derecho a percibir AAFF. "Asiste a las personas trabajadoras privadas de la libertad ambulatoria el derecho a gozar de la totalidad de los beneficios de la Seguridad Social inherentes al trabajo dependiente, en especial los previstos por las leyes 24.241 (jubilaciones y pensiones), 24.714 (asignaciones familiares), 23.660 (obra social), 23.661 (seguro de salud) y 24.013 (prestación de desempleo) y demás normas nacionales o provinciales concordantes o complementarias". Por todo lo expuesto, el trabajo prestado intramuros debe respetar la legislación laboral vigente, y por ello, cabe recordar que los internos trabajadores están incluidos dentro del régimen de la seguridad social, y son sujetos beneficiarios de las asignaciones familiares previstas en la ley 24.714". El Informe reconoce las dificultades existentes para el cobro de las AAFF y sostiene que no puede invocarse la inexistencia de contribuciones cuando esta es una obligación del empleador ${ }^{19}$.

Para comprender esta omisión debe recordarse que el ENCOPE tiene un rol central en este tema. ENCOPE apela a esta normativa para poder referirse al trabajo como parte de "talleres de labor terapia" (típicamente utilizados para tratamiento de afecciones físicas, psíquicas) y a los recibos que les entrega a los trabajadores que se denominan peculio (que los especialistas

\footnotetext{
${ }^{18}$ Para una discusión sobre este tema, cfr. Porta (2016); Tedeschi (2012)

${ }^{19}$ Para un detalle sobre la cuestión de Asignaciones Familiares en contextos de encierro, cfr. Borda (2014)
} 
Arcidiácono, P. Madres privadas de libertad (y de las Asignaciones Familiares). Resistencias burocráticas y actuación judicial. Derecho y Ciencias Sociales. Octubre 2017. No 17. Pgs 207-225 ISNN 1852-2971. Instituto de Cultura Jurídica y Maestría en Sociología Jurídica. FCJ y S. UNLP

en la materia lo asemejan a la "dádiva"). En la demanda se sostiene que este tipo de referencia normativa tiene el propósito eludir el cumplimiento de la ley laboral y todas las obligaciones involucradas. En la demanda y en las audiencias el SPF y ENCOPE no presentan argumentaciones extensas que se propongan justificar esta omisión. Es más, ante la pregunta insistente de los jueces de la Sala IV de la Cámara de Casación Penal en la audiencia del 18 de noviembre de 2015, las burocracias técnicas del SPF y ENCOPE respondieron con una frase idéntica, breve y contundente: "No corresponde pagar AAFF porque no es trabajo como el de la ley de contrato de trabajo". De esa manera dejan incluso sin utilizar el resto del tiempo otorgado por el tribunal para hacer uso de la palabra.

Lo cierto es que la PPN señala que la principal confusión radica en asimilar al ENCOPE con una empresa privada y alerta que desde 2011 se le asignan las partidas vinculadas con Fondos de Desempleo, AAFF, aportes previsionales y accidentes de riesgos de trabajo que deben ser previstas como un ítem en sus reservas presupuestarias. Sin embargo la población privada de libertad continúa en general quedando excluida aun en los casos en los que falta una condena firme (donde según la ley penal vigente se perdería la patria potestad).

Claramente, las entrevistas realizadas a los actores de las diferentes agencias, las audiencias e incluso los escritos ponen de manifiesto que el SPF (y el ENCOPE) son los actores de peso en el campo de las AAFF. El SPF que tiene a su cargo la función de garantizar la seguridad en prisión y custodiar la ejecución de la pena, tiene a su cargo (junto con el ENCOPE como organismos descentralizado) la gestión de todo aquello relativo al trabajo. Esto explica y retroalimenta la impronta del trabajo como elemento para garantizar la seguridad de prisión y no como parte de la protección de los derechos de los trabajadores.

ANSES se presenta como un actor secundario y desdibujado a lo largo de la causa cuando se trata de AAFF (a diferencia de lo que sucede en materia de AUH cuando adquiere protagonismo). De hecho, advirtió en reiteradas oportunidades que dichas transferencias deben ser recibidas por los trabajadores en contexto de encierro, señalándole al ENCOPE la necesidad de dictar una norma para que los trabajadores cobren AAFF (Dictamen 36.664 del 12 de septiembre de 2007). La opinión de ANSES en este punto debería resultar determinante, al ser la autoridad de aplicación del régimen de Asignaciones, sin embargo no lo es. Este dictamen sin embargo no tuvo ningún peso legal ni político.

No es un dato menor que en el marco de la audiencia en Comodoro Py, a la hora de tratar este tema, ANSES enviara un representante del “Área de Emisión de Normas y Requerimientos de Asignaciones no contributivas". Mientras que las argumentaciones de SPF se simplificaron a negar el trabajo en la prisión como se entiende en el medio libre, las explicaciones de ANSES 
Arcidiácono, P. Madres privadas de libertad (y de las Asignaciones Familiares). Resistencias burocráticas y actuación judicial. Derecho y Ciencias Sociales. Octubre 2017. No 17. Pgs 207-225 ISNN 1852-2971. Instituto de Cultura Jurídica y Maestría en Sociología Jurídica. FCJ y S. UNLP

se concentraron en cuestiones estrictamente vinculadas con las imposibilidades del "Sistema informático que no habilitaba el pago". Esta suerte de "metáfora informática" que apareció luego renovada en el proceso de ejecución de sentencia, tiene la forma de velo "a través del cual las burocracias se enmascaran detrás del funcionamiento de operaciones no humanas" (AUYERO, 2013) que dilata la espera de las madres privadas de libertad y sus hijos que aún no perciben Asignaciones Familiares.

\section{b-El "temor expansivo" o la "punta del ovillo"}

A la hora de finalizar este artículo aún resulta incierto el alcance del caso. ¿Cuáles son sus implicancias en la población que se encuentra alojada en otras unidades y la posibilidad (o no) de trascender el universo de las madres privadas de libertad que conviven con sus hijos? Los entrevistados de las diferentes agencias e informantes clave, visibilizanciertas potencialidades del caso para trascender el grupo comprendido en demanda.

Por un lado, quienes litigaron el caso hay expectativas. Una vez que los procedimientos para abonar las Asignaciones se concreten (cuentas personales, tarjetas de débito especiales, entre otras cuestiones), el "mecanismo" podría servir como "punta del ovillo" o "llave" para extender las Asignaciones a otros grupos de madres y a largo plazo a los restantes privados de libertad que trabajan en contextos de encierro y no reciben AAFF.

Por otro lado, para los, referentes entrevistados de ANSES o como se plasma en las apelaciones y en el voto desfavorable de un magistrado de la Cámara de Casación Penal, esto adquiere una connotación negativa.

Evalúan esta posibilidad con una suerte de "temor expansivo", que trascienda el mundo de las madres privadas de libertad y sirva como "punta de lanza" para el cobro en general de las Asignaciones para las personas privadas de libertad.

Un extracto del voto del Juez Gemignani, uno de los integrantes de la Sala IV De la Cámara de Casación Penal que se manifestó en disidencia sintetiza esta visión. Bajo argumentos autorrestrictivos y presupuestarios, evita avanzar en medidas de tipo colectivas o que impacten estratégicamente en transformación de políticas públicas. Señala “(...) no se cuenta con una estimación de la repercusión que la modificación por vía judicial del régimen analizado, aun cuando en el presente se trata de un reducido universo de personas, podría llegar a tener, de modo que la decisión que corresponda adoptar, deberá ser ejecutada en el marco de una intervención jurisdiccionalmente más amplia que la aquí evidenciada que posibilite una amplia coordinación de las circunstancias jurídicas en pugna. A esos fines corresponde que la Administración Nacional de la Seguridad Social (ANSeS) y al Ente de 
Arcidiácono, P. Madres privadas de libertad (y de las Asignaciones Familiares). Resistencias burocráticas y actuación judicial. Derecho y Ciencias Sociales. Octubre 2017. No 17. Pgs 207-225 ISNN 1852-2971. Instituto de Cultura Jurídica y Maestría en Sociología Jurídica. FCJ y S. UNLP

Cooperación Técnica y Financiera del Servicio Penitenciario Federal (ENCOPE) con la colaboración de los diversos actores en pugna, arriben a una solución consensuada en orden a la revisión de la pertinencia o no del cobro de los beneficios pretendidos"

Asimismo, esto puede captarse en su máxima expresión en la siguiente cita extraída del Recurso Extraordinario presentado por ANSES: "En el caso que aquí se ventila, el otorgamiento de los beneficios pretendidos a un colectivo que no constituye beneficiario expresamente determinado por la ley 24. 714 se pondría en crisis el Sistema Integrado Previsional Argentino (SIPA) ${ }^{20}$ instituido mediante las leyes 24463 y 26417 y en particular, el sistema de asignaciones familiares y asignación universal establecido en la ley 24.714. En efecto, de otorgarse las prestaciones en forma generalizada sin elementales controles sobre cuestiones básicas como ser: la filiación de las peticionantes respecto de los menores -que huelga recordar no se encuentra acreditada en autos- el riesgo de pago múltiple de una misma asignación que podría estar siendo percibida por el progenitor que no se encuentra cumpliendo condena alguna, etc., se estaría consagrando un acceso irrestricto e ilimitado a dichas prestaciones sin sujeción a límite o procedimiento alguno lo cual no resulta ni de la letra ni del espíritu de la ley."

Lo cierto, es que este "temor expansivo" que se manifiesta en los escritos y en las entrevistas convive con la propia lógica expansiva de ANSES en materia de Asignaciones, no sólo de AAFF desde 2004 sino más aún desde la creación de la Asignación Universal por Hijo en 2009.

Como veremos en el próximo punto, otros argumentos completan el escenario que permite comprender las resistencias y razones que sostuvieron esta exclusión. En el "mientras tanto", la sentencia que resulta favorable para el grupo en cuestión, actúa en simultáneo re codificando desigualdades sociales (Santos, 1998) al quedar restringida a este grupo de madres.

\section{c-La antinomia obrero/jubiladoversus delincuente}

\footnotetext{
"La discusión que jamás se había extinguido, se reanuda y con gran vivacidad hacia los años 1840-1845, época de crisis económica, época de agitación obrera, época también en que comienza a cristalizar la oposición del obrero y del delincuente. Hay huelgas contra los talleres de las prisiones (...) Hay también toda una campaña de prensa en los periódicos obreros: sobre el tema de que el gobierno favorece el trabajo de las prisiones para hacer que bajen los salarios 'libres', los inconvenientes son peores para las mujeres que no encuentran trabajo y son empujadas a la prostitución (...) "Esos pobres reclusos!!, diría aquel que apenas si
}

\footnotetext{
${ }^{20} \mathrm{El}$ resaltado es propio.
} 
Arcidiácono, P. Madres privadas de libertad (y de las Asignaciones Familiares). Resistencias burocráticas y actuación judicial. Derecho y Ciencias Sociales. Octubre 2017. No 17. Pgs 207-225 ISNN 1852-2971. Instituto de Cultura Jurídica y Maestría en Sociología Jurídica. FCJ y S. UNLP

habla de los obreros doradores, hay que haber matado o robado para despertar la compasión o el interés” (Foucault; [1976] 1999: 244).

Cualquier semejanza con la discusión contemporánea en Argentina es pura coincidencia.

¿Cómo se explica que el titular de ANSES durante la gestión de la Presidenta Cristina Fernández (Diego Bossio) no revirtió la exclusión en un contexto de expansión de las Asignaciones? ¿Por qué la gestión de Emilio Basavilbaso en ANSES durante la presidencia de Mauricio Macri promovía la extensión de las Asignaciones a sectores monotributistas llegaba a la Corte Suprema con este caso de madres privadas de libertad? Lo cierto es que a la hora de indagar sobre el rol de los decisores políticos en este caso, los entrevistados uniformemente apelan al "contexto político-electoral" y/o al "clima mediático".

Recordemos que el habeas corpus fue presentado en diciembre de 2014. En ese mismo mes, comenzó a difundirse públicamente la mencionada sentencia "Kepych" y los medios masivos instalaron y re-crearon en la agenda pública un discurso donde los derechos sociales de las PPL aparecían en competencia con los derechos sociales de quienes sin haber delinquido veían vulnerados sus derechos en el medio libre (los trabajadores). Sin pretensión de analizar el contenido de la comunicación mediática, sólo a modo de ejemplo resultaba frecuente encontrar titulares de este tipo “Acá están, ellos son... Los presos VIP que cobran sueldo y aguinaldo" (Clarin, 8 de diciembre 2014) ${ }^{21}$.

Esta visión atravesó la contienda electoral. Sergio Massa, ex titular de ANSES durante la gestión del Presidente Nestor Kirchner y candidato a presidente en octubre de 2015 por el Frente Renovador agregó la figura de los jubilados como antinómica de los "delincuentes o presos". "Lo único que falta es que los presos pidan aguinaldo y vacaciones" (La Nación, 5 de diciembre de 2014) ${ }^{22}$; "Al Gobierno le interesan más los presos que los jubilados"(La Nación, 27 de julio de 2015) $)^{23}$.

Frente a este escenario, el argumento de la "no conveniencia política/electoral" surgía en cada una de las entrevistas realizadas en todo el trabajo de campo. Cabe recordar que a poco tiempo de presentarse el habeas, el titular de ANSES (Diego Bossio) era candidato a diputado nacional por el oficialismo. “QQuién iba a querer pegar la figura de "Diego Bossio” a los

\footnotetext{
${ }^{21}$ https://www.clarin.com/ultimo-momento/aca-vip-cobran-sueldo-aguinaldo_0_SkK8KPcPmg.html. Página consultada el 25 de abril de 2017.

${ }^{22} \mathrm{http}: / /$ www.lanacion.com.ar/1749844-massa-lo-unico-que-falta-es-que-los-presos-pidan-aguinaldo-yvacaciones Página consultada el 25 de abril de 2017.

${ }^{23}$ http://www.lanacion.com.ar/1813908-massa-al-gobierno-le-interesan-mas-los-presos-que-los-jubilados Página consultada el 25 de abril de 2017.
} 
Arcidiácono, P. Madres privadas de libertad (y de las Asignaciones Familiares). Resistencias burocráticas y actuación judicial. Derecho y Ciencias Sociales. Octubre 2017. № 17. Pgs 207-225 ISNN 1852-2971. Instituto de Cultura Jurídica y Maestría en Sociología Jurídica. FCJ y S. UNLP

presos?", era una frase frecuente en las entrevistas a los diversos actores al interior de ANSES. Todo indicaba que no resultaba conveniente ni electoral ni políticamente para los propios decisores políticos de ANSES dar un paso en el universo de los reclamos de las PPL. Este aspecto relativiza o al menos pone en duda las visiones más optimistas sobre las potencialidades de la causa de expandirse a otros grupos y a otros centros de detención.

\section{4-Conclusiones}

En el campo de las tradicionales AAFF la exclusión de la población privada de libertad resulta generalizada, no sólo acotada al grupo que contempla la demanda judicial. Este aspecto resulta inescindible de las particularidades del trabajo en contexto de encierro. La lectura del caso sugiere que la lógica del "adentro/afuera" es el principal vector de desigualdad a la hora de negar el acceso a las prestaciones. Este grupo aparece como un límite ético y político en el medio de la masificación del sistema de Asignaciones en Argentina.

El caso en particular pone de manifiesto el rol clave de las burocracias técnico profesionales de las agencias del gobierno como ANSES, SPF (y ENCOPE) y sus significativos márgenes de actuación. Se convirtieron en actores centrales para negar el acceso a las AAFF (y también a la AUH) al disputar el alcance simbólico y operativo de las Asignaciones como derechos. Sobre todo una vez que se trasciende la formalidad de los escritos, sus argumentos "legales" resultan secundarios y emergen con toda potencia otras posiciones morales: resistencias, convencimientos y creencias sobre lo que es o no "trabajo". Sobre todo las burocracias técnico profesionales del SPF (y ENCOPE) se presentan como actores unificados en esta temática y defienden su legitimidad para actuar y monopolizar la gestión del trabajo, además del control de la seguridad en la prisión y la ejecución de la pena que son sus funciones principales.

Una lectura optimista sobre la causa habla de su potencial expansivo para abarcar a futuro al resto de la población privada de libertad. El incipiente proceso de ejecución de la sentencia insinúa que una vez despejadas las limitaciones "tecnológicas" el tema podría solucionarse globalmente.

Sin embargo, un acercamiento a la temática como la que se sostuvo a lo largo de estas páginas, indica que no es posible pensar una transformación en materia de Asignaciones en contexto de encierro, sin contemplar el margen de las burocracias, sus concepciones sobre estos temas y la evaluación que hacen los decisores políticos sobre la conveniencia (o no) política/electoral en un contexto mediático y político donde la expansión de los derechos sociales de las personas privadas de libertad tuvieron y aún tienen una connotación negativa. 
Arcidiácono, P. Madres privadas de libertad (y de las Asignaciones Familiares). Resistencias burocráticas y actuación judicial. Derecho y Ciencias Sociales. Octubre 2017. No 17. Pgs 207-225 ISNN 1852-2971. Instituto de Cultura Jurídica y Maestría en Sociología Jurídica. FCJ y S. UNLP

Desde esta mirada los efectos de la causa dejan más bien una serie de interrogantes sin resolver.

\section{Bibliografía}

Arcidiácono, P.; Espejo, N. y Rodriguez Garavito, C. (coordinadores) (2010): Derechos Sociales: justicia, política y economía en América Latina, Siglo del Hombre editores, Bogotá.

Arcidiácono, P.; Gamallo, G.; Pautassi, L. y Straschnoy, M.(2015) ”Brechas de bienestar en el acceso a las prestaciones sociales. Acerca de las asignaciones familiares y la asignación universal por hijo en Argentina", en Universidad y Sociedad. Desafíos de la Investigación interdisciplinaria, EUDEBA-Programa Interdisciplinario de la Universidad de Buenos Aires sobre marginaciones Sociales (PIUBAMAS), Buenos Aires.

Arcidiácono, P. (2016) "Expansion and Exclusion in the Universal Child Allowance Programme in Argentina. Litigationonaccesformothersdeprived of liberty", en SUR - Revista Internacional de Direitos Humanos, publicada pela Conectas Direitos Humanos, Número 24,

Abdó Feréz, C. (2014). "La política y la juristocracia" en Sociedad; Ciudad Autónoma de Buenos Aires; Año: 2014 vol. 33.

Abramovich, V. y Pautassi, L. (2009).La revisión judicial de las políticas sociales. Estudio de casos en argentina, Ciudad de Buenos Aires: Ediciones del Puerto.

Auyero, Javier (2013).Pacientes del Estado, Ciudad Autónoma de Buenos Aires: Eudeba.

Barrera, Leticia (2014). "Burocracia y Derecho: Reflexiones sobre el rol de los documentos en la construcción del conocimiento jurídico", en Sociedad; Lugar: Ciudad Autónoma de Buenos Aires Año: 2014 vol. 33.

Bertranou, Fabio y Bonari, Damián (Coord.) (2005). Protección social en Argentina. Financiamiento, cobertura y desempeño, 1990-2003. Santiago de Chile: CEPAL.

Borda, Rodrigo (2014).El régimen de asignaciones familiares y la situación de las personas privadas de su libertad. ¿La cárcel es un límite infranqueable para los derechos (sociales)? En Revista de Derecho Penal y Procesal Penal No 4, año 2014, Ciudad Autónoma de Buenos Aires, Abeledo Perrot.

Bourdieu Pierre (2000).La Fuerza del Derecho. Elementos para una sociología del campo jurídico, Bogotá: Ediciones Uniandes: Siglo del Hombre Editores.

Comisión Especial de Estudio sobre las Condiciones de Vigencia y Estado de las Relaciones Laborales en el Marco del Trabajo Prestado en Condiciones de Encierro de las Personas Privadas de su Libertad Ambulatoria del MTEySS (2015), Trabajo en cárceles, Ciudad de Buenos Aires: MTEySS.

Foucault, Michael [1976] (1999). Vigilar y castigar. Nacimiento de la prisión, México,

Siglo XXI.

Hintze, Susana y Costa, María Ignacia (2011). La reforma de las asignaciones familiares 2009: aproximación al proceso político de la transformación de la protección. En Danani, Claudia y Hintze, Susana (coords.), Protecciones y desprotecciones: la seguridad social en la Argentina 1990-2010 (pp.153-187). Buenos Aires: Universidad Nacional de General Sarmiento. 
Arcidiácono, P. Madres privadas de libertad (y de las Asignaciones Familiares). Resistencias burocráticas y actuación judicial. Derecho y Ciencias Sociales. Octubre 2017. № 17. Pgs 207-225 ISNN 1852-2971. Instituto de Cultura Jurídica y Maestría en Sociología Jurídica. FCJ y S. UNLP

MTEySS-Ministerio de Trabajo, Protección y Seguridad Social en la Argentina. Resultados de la Encuesta Nacional de Protección y Seguridad Social 1a edición de 2011 (2014), Ciudad Autónoma de Buenos Aires: Ministerio de Trabajo, Empleo y Seguridad Social.

Boletín Estadístico de la Seguridad Social, Segundo trimestre, (2016), Ciudad Autónoma de Buenos Aires: Ministerio de Trabajo, Empleo y Seguridad Social.

Perelmiter, L. (2008). “¿Es posible la debilidad estatal? Notas de investigación sobre la construcción del Estado en política social Revista Papeles de Trabajo; Lugar: Buenos Aires; Año: 2008 vol. 1.

Porta, E. (2016).El trabajo en contexto de encierro, Ciudad Autónoma de Buenos Aires, Ediar.

Procuración Penitenciaria De La Nación, Centro De Estudios Legales Y Sociales Y Ministerio Público De La Defensa De La Nación, (2011),Mujeres en prisión. Los alcances del castigo, Buenos Aires, Siglo XXI.

Procuración Penitenciaria De La Nación (2015), Informe Anual 2015. La situación de los derechos humanos en las cárceles federales de la Argentina, Ciudad de Buenos Aires: PPN.

Santos, B (1998). De la mano de Alicia. Lo social y lo político y en la posmodernidad, Bogotá: Siglo del Hombre Editores.

Tedeschi, S. (2012). "Los derechos sociales de las personas privadas de libertad y el sistema penitenciario", en Mariano Gutierrez, Lápices o rejas, Ciudad Autónoma de Buenos Aires, Del Puerto.

Vismann, C.(2008), Files: Law and Media Tecnology, Stanford University Press, Stanford, California.

\section{Instrumentos internacionales sobre privados de libertad (citados)}

Convención Americana de Derechos Humanos. Disponible en: https://www.oas.org/dil/esp/tratados_b32_convencion_americana_sobre_derechos_humanos.h tm

Convenio $\mathrm{N}^{\circ} 29$ sobre trabajo forzoso de la OIT. Disponible en: http://www.ilo.org/dyn/normlex/es/f?p=NORMLEXPUB:55:0::NO::P55_TYPE,P55_LANG, P55_DOCUMENT,P55_NODE:CON,es,C029,/Document

Principios básicos para el tratamiento de los reclusos de las Naciones Unidas (1990). Disponible en: http://www.ohchr.org/SP/ProfessionalInterest/Pages/BasicPrinciplesTreatmentOfPrisoners.as px

Reglas de Brasilia sobre acceso a la justicia de las personas en condición de vulnerabilidad (XIV Cumbre Judicial Iberoamericana), (2008). Disponible en:http://www.cumbrejudicial.org/c/document_library/get_file?uuid=6fe6feca-4300-46b2a9f9-f1b6f4219728\&groupId=10124

Reglas mínimas para el tratamiento de los reclusos de las Naciones Unidas (1977). Disponible en http://www.ohchr.org/SP/ProfessionalInterest/Pages/TreatmentOfPrisoners.aspx

Reglas de las Naciones Unidas para el tratamiento de las reclusas y medidas no privativas de la libertad para las mujeres delincuentes (Reglas de Bangkok) (2011). Disponible en https://www.unodc.org/documents/justice-and-prison-

reform/Bangkok_Rules_ESP_24032015.pdf 